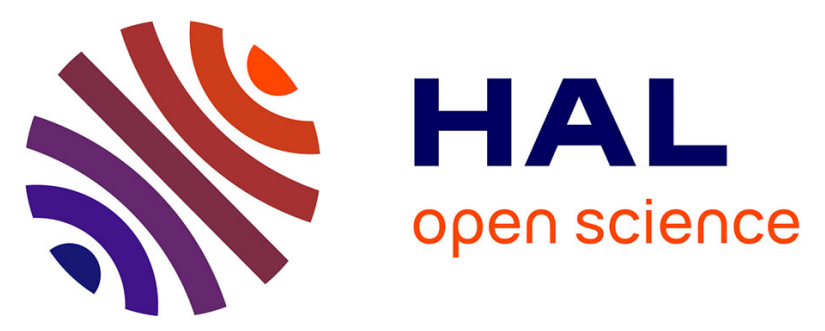

\title{
Citizen science involving farmers as a means to document temporal trends in farmland biodiversity and relate them to agricultural practices
}

Olivier Billaud, Rose-line Vermeersch, Emmanuelle Porcher

\section{- To cite this version:}

Olivier Billaud, Rose-line Vermeersch, Emmanuelle Porcher. Citizen science involving farmers as a means to document temporal trends in farmland biodiversity and relate them to agricultural practices. Journal of Applied Ecology, 2020, 10.1111/1365-2664.13746 . mnhn-02947862

\section{HAL Id: mnhn-02947862}

\section{https://hal-mnhn.archives-ouvertes.fr/mnhn-02947862}

Submitted on 24 Sep 2020

HAL is a multi-disciplinary open access archive for the deposit and dissemination of scientific research documents, whether they are published or not. The documents may come from teaching and research institutions in France or abroad, or from public or private research centers.
L'archive ouverte pluridisciplinaire $\mathbf{H A L}$, est destinée au dépôt et à la diffusion de documents scientifiques de niveau recherche, publiés ou non, émanant des établissements d'enseignement et de recherche français ou étrangers, des laboratoires publics ou privés. 
1 Citizen science involving farmers as a means to document temporal trends in farmland biodiversity

2 and relate them to agricultural practices.

3 Authors: Olivier Billaud ${ }^{1 *}$, Rose-Line Vermeersch ${ }^{1}$, Emmanuelle Porcher $^{1}$

4 Author details:

$5{ }^{1}$ Centre d'Ecologie et des Sciences de la Conservation (CESCO), Muséum national d'Histoire naturelle,

6 Centre National de la Recherche Scientifique, Sorbonne Université, Paris, France

7 Correspondence to :

8 * Olivier Billaud, CESCO - CP 135, Muséum national d'Histoire naturelle, 43 rue Buffon - 75005 Paris,

9 +33-(0)140798134, olivier.billaud@edu.mnhn.fr

10 
Abstract

(1) Agricultural intensification is often recognized as a major driver of the decline of wild biodiversity in farmland. However, few studies have managed to collect relevant data to link the temporal dynamics of farmland biodiversity to the characteristics of intensive agriculture over large geographical areas.

(2) We used 7 years of data from a French citizen science programme, wherein 1,216 farmers monitored biodiversity in 2,382 fields encompassing field crops, meadows, vineyards or orchards, to examine the temporal trends in abundance of five taxonomic groups of invertebrates (solitary bees, earthworms, butterflies, beetles, molluscs) and their links with agronomic practices and surrounding landscape.

(3) We observed significant temporal trends in abundance for many taxonomic groups and in many crop types. Flying taxa (solitary bees and butterflies) were generally declining, while the trends of soil taxa were more variable. Most trends were significantly related to farming practices or landscape features. We observed a negative link between use of synthetic inputs (pesticides, mineral fertilization) and the trend in abundance of flying taxa in field crops, while in meadows organic or mineral fertilization was the main explanatory practice, with contrasting relationships across taxonomic groups. Besides, the trend in abundance of beetles and molluscs was more positive in permanent versus temporary meadows. Finally, in vineyards the trend in abundance of solitary bees was positively related to the presence of woodland in the landscape, whereas the reverse was true in meadows.

(4) Synthesis and applications. Our results provide further support for the role of citizen science as a promising source of large-scale spatial and temporal data in farmland, contributing to the identification of agronomic practices that can help mitigate biodiversity decline. Our analyses suggest that reducing chemical inputs may not only reduce the decline in bees and butterflies, but sometimes even promote their regrowth. Increasing organic fertilization may foster bee and beetle abundance in meadows but reduce mollusc abundance, while 
preventing ploughing of meadows may promote soil invertebrate abundance. Finally, such citizen science programmes engage farmers to undertake monitoring. Whether such group engagement may also contribute to biodiversity conservation by raising farmers' awareness remains to be addressed.

Keywords: bees, beetles, butterflies, earthworms, fertilization, landscape, mollusks, pesticides

\section{Additional abstract / Résumé}

(1) L'intensification de l'agriculture est reconnue comme un facteur majeur du déclin de la biodiversité sauvage dans les terres agricoles. Cependant, peu d'études ont pu relier les changements temporels de la biodiversité agricole aux pratiques agricoles.

(2) Grâce aux données issues de l'Observatoire Agricole de la Biodiversité, un programme de science participative ayant rassemblé 1216 agriculteurs entre 2011 et 2017, pour un total de 2382 parcelles comprenant des grandes cultures, des prairies, des vignobles ou des vergers, nous avons étudié les tendances temporelles de l'abondance de cinq groupes d'invertébrés (abeilles solitaires, vers de terre, papillons, carabes, mollusques) et leurs liens avec les pratiques agronomiques et le paysage environnant.

(3) Nous avons observé des variations temporelles significatives de l'abondance pour plusieurs groupes taxonomiques et dans de nombreux types de cultures. Les taxons volants (abeilles solitaires et papillons) sont en général en déclin, tandis que les tendances des taxons terrestres sont plus variables. La plupart des tendances sont significativement corrélées aux pratiques agricoles ou au paysage. L'utilisation d'intrants de synthèse (pesticides et fertilisation minérale) est corrélée au déclin des taxons volants dans les grandes cultures, tandis que dans les prairies, la fertilisation organique et/ou minérale est la principale pratique explicative, avec des relations contrastées entre les groupes taxonomiques. En outre, les carabes et des mollusques sont en augmentation dans les prairies permanentes mais en déclin dans les prairies temporaires. Enfin, dans les vignobles, les 
variations d'abondance des abeilles solitaires sont positivement reliées à la présence de bois dans le paysage, alors que l'inverse est vrai dans les prairies.

(4) Synthèse et applications. Nos résultats confortent le rôle de la science citoyenne comme source prometteuse de données à grande échelle spatiale et temporelle dans les espaces agricoles, contribuant à l'identification des pratiques agronomiques qui peuvent aider à atténuer le déclin de la biodiversité. Nos analyses suggèrent que la réduction des intrants chimiques peut non seulement réduire le déclin des abeilles et des papillons, mais parfois même favoriser leur augmentation. Une fertilisation organique plus importante peut favoriser l'abondance des abeilles et des carabes dans les prairies mais réduire l'abondance des mollusques, tandis que le non-retournement des prairies peut favoriser l'abondance des invertébrés du sol. Enfin, ces programmes de science citoyenne incitent les agriculteurs à observer la biodiversité de leurs parcelles. Reste à savoir si cet engagement collectif des agriculteurs peut également contribuer à la conservation de la biodiversité par une plus forte sensibilisation sur le sujet. 


\section{1 | Introduction}

Agricultural intensification is recognized as a major driver of the current biodiversity decline for insects (Sánchez-Bayo \& Wyckhuys, 2019; Seibold et al., 2019), birds (Stanton, Morrissey, \& Clark, 2018) or soil biota (Ponge et al., 2013). Different mechanisms may explain this agriculture-driven biodiversity loss, including non-target effects of pesticides (Zaller \& Brühl, 2019), fertilization (Haddad, Haarstad, \& Tilman, 2000), tillage (Roger-Estrade, Anger, Bertrand, \& Richard, 2010), landscape simplification and homogenization (Gamez-Virues et al., 2015), etc. However, proving a causal link between practices and biodiversity is often challenging.

Several limitations of studies relating biodiversity to farming practices are responsible for this lack of conclusiveness. First, such studies are often restricted in space and time or focus on specific taxa, which hampers generalization (see Cardinale et al. 2011 for a review). In contrast, the few studies that benefit from large-scale, long-term biodiversity monitoring data have limited information on agronomic practices. For instance, Hallmann et al., (2017) could only speculate on the role of agriculture in the massive decline in insect biomass, because they lacked accurate data on agriculture. Second, most studies measuring the impacts of potential drivers assume space-for-time substitution (SFT). SFT can be relevant to study the effects of slow environmental changes, by comparing systems at different stages of development (Pickett, 1989). Such approach assumes that the temporal dynamics of the sites can be ignored and that spatial patterns are due to different ecological equilibria (Damgaard, 2019). These assumptions are true only when ecological processes are quick compared to environmental changes (Damgaard, 2019), which may not apply for biodiversity dynamics in rapidly changing agroecosystems (Jackson \& Blois, 2015; Kratz, Deegan, Harmon, \& Lauenroth, 2003).

To our knowledge, only a handful of studies addressing the impacts of agricultural practices on biodiversity included a true temporal dimension. Among them, Hallmann et al. (2014) linked the introduction of neonicotinoids to a negative trend in insectivorous bird populations by comparing 
different periods of surveys (before/after). Berger et al. (2018) observed a relationship between changes in glyphosate application modes and amphibian migration. Finally Seibold et al. (2019) showed a general decline of arthropods driven by land-use intensification at large spatial extent. These temporal approaches to elucidate the role of agriculture in biodiversity changes are few because they require gathering temporal and spatial data at large scales, which is labor and time intensive. A way to solve this problem may be to capitalize on the recent expansion of citizen science for biodiversity monitoring, which can involve geographically dispersed observers during several years (Chandler et al., 2017).

In this article, we rely on a citizen science program designed for farmers to study temporal trends in abundance of several taxonomic groups (solitary bees, earthworms, molluscs, beetles and butterflies). We investigated how the temporal trends in abundance of these groups are correlated with both agronomic practices and surrounding landscape. Documenting such relations may help identify possible levers for the conservation of invertebrates in farmland, through changes in agricultural practices.

\section{2 | Materials and methods}

\section{1 | Citizen science to monitor farmland biodiversity}

The Farmland Biodiversity Observatory (FBO) is a French citizen science programme launched in 2011, wherein 1,216 farmers monitored biodiversity in 2,382 fields, thereby ensuring a good representation of the diversity of farming practices and crop distribution across France (Fig. S1A). Four types of crops are monitored: field crops (1,515 fields), meadows ( 705 fields), vineyards (538 fields) and orchards (240 fields). We used data collected between 2011 and 2017. As in most citizen science programmes, participant turnover is high in $\mathrm{FBO}$, with a mean duration of participation from 1.22 to 1.39 years, depending on the taxonomic group monitored (Fig S1B). However, the number of newly involved farmers each year is relatively stable through time, such that the dataset provides a 
"series of pictures" of biodiversity throughout France. Note S1 provides more information on FBO, the farmers involved, and ongoing research on how this programme changes farmer perceptions of biodiversity.

\section{2 | Biodiversity data}

FBO focuses on four taxonomic groups chosen for their interconnections with agriculture: solitary bees (pollination services, Potts et al., 2016; Winfree, Williams, Dushoff, \& Kremen, 2007), butterflies (sensitive to changes in land use at the landscape scale, Dover \& Settele, 2009; Nilsson, Franzen, \& Pettersson, 2013), earthworms (soil fertility, Lemtiri et al., 2014) and soil invertebrates (pests and beneficial organisms, Kromp, 1999; Symondson, Sunderland, \& Greenstone, 2002). Monitoring protocols are simple, yet standardized. Observers can access keys to identify individuals to either functional group or taxonomic rank (genus and sometimes species level). Bee monitoring uses two trap nests of 32 tubes each placed in the field edge, facing south. Observers monitor nest occupancy by counting sealed tubes (Fig. S2C). For butterflies, observers walk a 10 minutes transect (100-300m) on the field edge, recording all individuals flying in a $5 \times 5 \times 5 \mathrm{~m}$ cube around them (Fig. S2A). To monitor soil invertebrates, three wooden cover-boards of $30 \times 50 \mathrm{~cm}$ are laid on the ground, two at the edge and one at the center of the plot (at 50m of the two others) (Fig. S2B). The observer quickly lifts the board to count all invertebrates; identification focuses on beetles and mollusks but other invertebrates are also reported. Finally, earthworms are sampled through three $1 \mathrm{~m}^{2}$ replicates located $6 \mathrm{~m}$ apart inside the field. Each replicate is watered twice with $10 \mathrm{~L}$ of a mustard solution (Fig. S2D). Earthworms expelled to the surface by the irritant solution are collected, counted and sorted into four functional groups: epigeic, black- and red-headed anecic and endogeic (Bouché, 1972).

In FBO, bees were monitored in 1,345 fields, butterflies in 727 fields, soil invertebrates in 807 fields and earthworms in 685 fields (Fig. S3 shows the distribution of monitoring protocols across crop types). The number of annual surveys per field varies across protocols. In theory, earthworms are 
sampled only once in winter or early spring, bees and invertebrates are monitored once a month between February and November, and butterflies are monitored five times per year between May and September. However, some observers may skip some of the surveys. To handle this variation in the number of observations per field and year, we did not work on annual summaries of biodiversity data, but chose to use individual surveys. For each group we focused on the total abundance, since most individuals cannot be identified to species level in the monitoring protocols. Moreover, abundance is more sensitive to environmental changes than diversity (Pereira et al., 2013).

\section{3 | Practices and landscape data}

Farmers also provide information about the landscape surrounding the field and their agricultural practices (Table S1 shows all variables associated with the protocols and crops). Some information is common to all plots: pesticide use (insecticide, herbicide, fungicide, molluscicide, others), fertilization (organic and mineral) and amendment (organic and calcium), which are provided as a number of applications. The surrounding landscape is described via field edge types (wood-fringe, hedge, grassy strip, roadside, ditch, flower strip, crop, other) and neighbouring land use (meadow, wood, urban, pond, crop, other). The field edges described are those close to the trap nests and transect for bees and butterflies; all edges for earthworms and invertebrates. Other information is only relevant for some types of crops: tillage (direct sowing, shallow or deep ploughing) in field crops, management of inter-rows (bare, partly grassy, grassy) in vineyards and orchards and use (mowing, pasture, mix), type (temporary or permanent) and age in meadows. Complementary protocol-specific information includes: distance to the nearest tree for earthworms, flowers in the crop and edges for butterflies and vegetation height for bees. Soil attributes (earthworms and invertebrates) and weather (butterflies, earthworms and invertebrates) are also collected. We computed degree-day (cumulative sum of temperature over zero) for each day using data from Cornes, Schrier, Besselaar, \& Jones (2018) and the R package climateExtract (Schmucki, 2020). 
179 Agricultural practices, as well as landscape variables, are often correlated with one another due to

180 the consistency of agronomic systems. To circumvent this problem, we summarized practices and 181 landscape variables with multivariate analyses. We used a principal component analysis (PCA) on

182 fertilization and pesticide use. We considered each crop type separately because they are associated

183 with contrasting production systems that use different amounts and classes of pesticides and

184 fertilization. These differences were easily seen on a PCA on all fields (Fig. 1A-B). However, regardless

185 of crop type, we observed the same general pattern in the outputs of the PCA, with the two main 186 axes easily interpreted as a "chemical treatment axis" (mostly pesticides and mineral fertilization)

187 and an "organic fertilization" axis, respectively (Fig. 1C-D-E-F). In the following, we therefore used the coordinates of fields on these axes as two uncorrelated variables describing the diversity of practices (Fig. 1C-D-E-F).

In the same way, we applied a multiple correspondence analysis (MCA) on binary landscape variables (presence / absence of elements in the edges or neighbouring land use) to summarize landscape diversity around fields. We analysed taxonomic groups separately because protocols differ in the number of surveyed field edges (see above). Nonetheless, for all protocols, one of the two first axes was interpreted as proximity to woodland (Fig. S4-5-6-7). The meaning of the other axis was more variable. For bees, butterflies, beetles and molluscs, it singled out the category "other" of the surrounding landscape and was not easily interpretable. For earthworms, it contrasted the presence of a pond versus adjacent crops (Fig. S4-5-6-7). 


\section{5 | Statistical modelling to correlate temporal trends in group abundance with practices and} landscape

To investigate the temporal trends in abundance per taxonomic group and their correlation with farming practices and landscape variables, we used generalized linear mixed models (GLMM) (Bolker et al., 2009). We assumed a negative binomial distribution of the data to take into account overdispersion. We started from a complete model with year, practice and landscape variables (the latter two being described by the first axes of the multivariate analyses), and their interactions, plus relevant additional covariates depending on the taxonomic group (hereafter "control covariates", Table S1) and a random effect of field. Practices were represented by the two axes of the PCA plus crop type-dependent variables (Table S1). We also tested alternative models using the total number of pesticide and (organic and mineral) fertilizer applications, instead of PCA axes, as a proxy for intensification. Axes 1 and 2 of the MCA reflected the surrounding landscape (Fig. S4-5-6-7). The general structure of the model was the following:

$$
\begin{aligned}
\log \left(\mu_{A B}\right) & =\beta_{0}+\beta_{1} \text { Year }+\beta_{2} \text { Axis } 1_{P C A}+\beta_{3} \text { Axis } 2_{P C A}+\beta_{4} \text { Axis } 1_{M C A}+\beta_{5} \text { Axis } 2_{M C A} \\
& +\beta_{6 x} \text { SpecificPractices }+\beta_{7 x} \text { Covariates }+\beta_{8} \text { Year: Axis } 1_{P C A} \\
& +\beta_{9} \text { Year: Axis } 2_{P C A}+\beta_{10} \text { Year: Axis } 1_{M C A}+\beta_{11} \text { Year: Axis } 2_{M C A} \\
& +\beta_{12 x} \text { Year: SpecificPractices }+ \text { Field }
\end{aligned}
$$

With $\beta_{j}$ the regression coefficients and Field $d_{i}$ the field-specific random effect. "Specific practices" (tillage, inter-row...) and covariates (weather conditions, GPS coordinates...) varied depending on protocol and type of crops (Table S1). All numerical variables were scaled. We selected variables using backward stepwise elimination from a complete model and significance of the change in loglikelihood as a criterion. We checked that all the "control" covariates had a consistent relationship with abundance, e.g. more abundant bees in the South or more abundant butterflies with lower wind (Tables 1-5 and S2-6). As for earthworms, models were GLM since the random field effect was not significant. We used the R package buildmer (Voeten, 2020). 
Of five taxonomic groups and four crop types, we analysed only 18 separate models out of 20

because we discarded earthworm data in orchards and vineyards, which were too few (some years with fewer than 10 surveys).

We diagnosed the fit of the models using the DHARMa package (Hartig, 2020). Over the 18 separate models of crops and taxonomic groups, all QQ plots were acceptable upon visual inspection. No Kolmogorov-Smirnov deviation test was significant, except for bees in field crops, for which the significant deviation was visually small. The residuals were significantly but moderately spatially autocorrelated (Table S17); introducing a covariance structure in the models did not modify the results (not shown). Variance inflation factors (VIF), computed using the package performance (Lüdecke, Makowski, Waggoner, \& Patil, 2020), were generally below 2 (Tables S7-16) except for artificially structured variables (e.g. degree days and squared degree days) and in models with a significant effects of meadows use or type. Removing these variables did not change the results for other variables (not shown). The models explained a fair amount of the variability in abundance, as estimated following Nakagawa, Johnson, \& Schielzeth (2017), although ca. 2/3 resided in the random effect: from 0.1 to 0.35 without, and from 0.43 to 0.85 with the random field factor. Lastly, we analyzed interaction terms using the package ggeffects (Lüdecke, 2018), which computes marginal effects of each variable with all others at their mean (quantitative variables) or at representative values (qualitative variables) from statistical models (Figs. 2-4).

\section{3 | Results}

The 1,216 farmers provided multi-year data from their fields on five taxonomic groups and in four crop types, and the overall analysis showed that there were significant temporal trends in biodiversity abundance in 16 of the 18 analyses. Some trends are related to farming practices or surrounding landscape. Tables 1-5 display a summary of the models using the PCA axes ("chemical treatment" and "organic fertilization") as proxy for farming practices, while Tables S2-S6 give a 
summary of the models using the number of applications of pesticides and fertilization. For each combination of crop type and taxonomic group, these two types of model may differ slightly. In the following, we focus on results that seem most robust, i.e. significant in the two types of models, but we illustrate all significant interactions in Figures S11-14.

\section{1 | Solitary bees}

The abundance of solitary bees appeared to be declining significantly in all crops but vineyards, and these declines were related to farming intensity or landscape structure (Tables 1 and S2). Conversely, the trend was positive in vineyards. Declines were stronger in fields with more pesticide use or more mineral fertilization (effects are statistically difficult to separate) in field crops (Figs. 2 and S8). On the other hand, bee declines were less steep with more organic fertilization (field crops, meadows) as well as in vineyards closer to woodland (Figs. 4 and S10). Conversely bee decline was stronger in meadows closer to woodland.

\section{2 | Butterflies}

The abundance of butterflies declined in field crops and vineyards and increased in meadows (Tables 2 and S3). Declines were related to farming intensity, but in opposite ways: as with bees, the trend in field crops was negatively correlated with the use of pesticides or mineral fertilization (Figs. 2 and S8). Conversely, the decline in vineyards was stronger in fields with fewer pesticide applications. No temporal trend was identifiable in orchards, but sample size was small ( $N=213$ for 37 fields).

\section{3 | Earthworms}

The abundance of earthworms showed a temporal decline in meadows only that did not vary with practices or landscape (no significant interactions, Tables 3 and S4, Figs. 3 and S9). However, the abundance of earthworms was significantly and positively related to a reduced tillage in field crops, as well as to organic fertilization and meadow age in meadows. 


\section{4 | Beetles}

The abundance of beetles increased significantly in field crops and vineyards and decreased in meadows and orchards (Tables 4 and S5). Declines in meadows and orchards were stronger in fields with more mineral fertilization (or pesticides in orchards, effects are difficult to separate) (Figs. 3 and S9). Finally, the decline in meadows was detected in temporary but not in permanent grasslands, where we observed a stronger increase in fields with more organic fertilization.

\section{5 | Molluscs}

As with beetles, the abundance of molluscs increased significantly in field crops and vineyards and decreased in meadows and orchards (Tables 5 and S6). Increases in vineyards were stronger in fields with more mineral fertilization or pesticides (effects are difficult to separate) but less organic fertilization. Declines in meadows were stronger in fields with more organic fertilization and in temporary versus permanent meadows (Figs. 3 and S9).

\section{4 | Discussion}

In this study we documented significant correlations between temporal trends in biodiversity abundance and in-field agricultural practices or wider landscape variables, across the whole of France thanks to participation of farmers in citizen science. In the following, we first compare our results with the existing literature using professionally collected data, contrasting flying versus soil taxa, and discuss the possible limitations related to the participatory nature of the data. We then examine how citizen science engaging farmers in monitoring of biodiversity can help pinpoint possible levers for the conservation and even restoration of invertebrates in agroecosystems through modifications of farming practices. 

related with agricultural practices

Of the five groups monitored, we observed a general negative trend in abundances, in particular for the two flying taxa with relatively long-distance movements (butterflies and solitary bees). These findings are in line with recent studies showing a decline in bees and butterflies, whether on a local (Hallmann et al., 2019), regional (Habel, Trusch, Schmitt, Ochse, \& Ulrich, 2019), national (Dooren, 2019) or global scale (Klink et al., 2020; Sánchez-Bayo \& Wyckhuys, 2019). Soil taxa, including potentially flying species but with short-distance daily movements, such as beetles, show a more mixed picture, with a temporal decline in abundance in meadows and orchards but a more surprising increase in field crops and vineyards. One major question is whether these trends reflect true variations in arthropod abundance in farmland, or are partly caused by temporal changes in the sample of fields surveyed each year, owing to the turnover of FBO participants. Two points discard the latter explanation. First, the general trend in abundance was negative, which could have been caused by a temporal increase in the fraction of fields under intensive farming in the FBO sample. Yet, if anything, the tendency in the FBO sample is that of an increase in the fraction of fields under organic farming consistent with the national trend (Note S1). Second, we did not analyze trends on raw data, but in a model including interactions with farming practices or landscape, thereby controlling for temporal changes in the latter variables.

Our ability to relate temporal trends in biodiversity with local agricultural practices contrasts with most previous studies. Our results are generally consistent however with numerous smaller-scale studies using the SFT assumption: stronger declines in fields with more synthetic inputs (mineral fertilization and pesticides) or in more homogeneous landscapes in most cases, but with some exceptions. Fertilization affects habitat quality via enrichment and sorting of competitive plant species. This may reduce the diversity and amounts of food for pollinating insects (e.g. bees and butterflies in field crops) and phytophagous species (e.g. molluscs in meadows). In some cases, 
however, increased plant biomass and leaf nitrogen content associated with fertilization can result in

328 increased invertebrate abundance, as observed e.g. by Haddad, Haarstad, \& Tilman (2000) and in

329 several instances in FBO: for molluscs with mineral fertilization in vineyards, as well as for bees and beetles with organic fertilization in meadows.

331 Pesticides often have non-target negative effects on invertebrates, demonstrated in the lab

332 (Desneux, Decourtye, \& Delpuech, 2007; Henry et al., 2012; Mulé, Sabella, Robba, \& Manachini, 2017) or in fields (Mulé et al., 2017), through direct mortality or multiple sublethal effects (Brittain \&

Potts, 2011; Desneux et al., 2007). Such effects may explain the negative relationship observed between pesticide use and trends in abundance of bees and butterflies in field crops. We found a more surprising positive correlation with butterfly abundance trends in vineyards. This is consistent with Muratet \& Fontaine (2015) who observed the same positive relationship in gardens with fungicides and Bordeaux mixture - two products highly used in vineyards - on butterflies and bumblebees. A hypothesis would be that plants protected from pests allocate more resources to nectar production.

Finally, proximity to woodland has mixed effects on solitary bees. The positive effect in vineyards is in line with numerous studies such as Carrié, Andrieu, Ouin, \& Steffan-Dewenter (2017). For some bee species, semi-natural landscape elements such as forests provide nesting sites and long-lasting food sources (Hopfenmüller, Steffan-Dewenter, \& Holzschuh, 2014) as well as a high connectivity in the

345 landscape. Decline of bee abundance in meadows close to woodland is consistent with Winfree, 346 Griswold, \& Kremen (2007) and may be explained by the lower quality of forests vs. farmland for bee 347 species that are likely specialists of open habitats.

348 Although these results corroborate previous knowledge and go beyond by relating biodiversity 349 trends with in-field practices, this approach suffers some limitations, some of which are inherent to 350 citizen science. As in many studies, including professional ones, our results are correlative and do not 351 formally demonstrate a causal relationship between agricultural practices or surrounding landscape 
and biodiversity. For example, a positive relationship between pesticide use and abundance of soil taxa may arise because pest outbreaks trigger pesticide use, which we are not able to differentiate from a positive effect of pesticides on these groups. This limitation could be partly overcome with time and a higher fidelity of participants: with longer time series, the dataset would contain a larger number of events of changes in practices. Such events could be used to analyse in more detail the impact of changing practices on biodiversity in real time, in an experimental-like manner. Second, the effects of pesticides and mineral fertilization were often not distinguishable from each other. This is related to the first point: across farming systems, pesticide and fertilizer uses are strongly correlated with each other. This multicollinearity undermines our ability to differentiate the relative contribution of each practice, a problem that could be partly alleviated again by real-time monitoring of changes in practices. Another option would be to collect higher resolution data on chemical products used (date and mode of application, quantity...), beyond a mere number of applications. Finally, data collection by non-taxonomists implies that in most cases, specimens could not be identified to species level. This may hamper our understanding of the ecological mechanisms influencing abundance trends in broad taxonomic groups containing species with contrasting ecological preferences. For example, some groups could be dominated by a single successful species. Alternatively, landscape may matter for some large but relatively rare ground beetles, but mixing them with smaller species with limited dispersal ability masked possible correlations with landscape structure.

\section{2 | Promising levers for invertebrate conservation in agricultural landscapes}

Our study pinpoints two key levers for invertebrate conservation in agroecosystems: i) identification of practices that may restore biodiversity ii) involvement of farmers in biodiversity monitoring; farmers are the main, albeit not the sole, social group with impacts on farmland biodiversity, and they have the agency to change practices. 
Despite the above limitations, this study illustrates that citizen science can be a powerful tool to gather extensive ecological datasets allowing research at multiple spatio-temporal scales and the identification of levers for invertebrate conservation. Although collected via simplified sampling protocols, the data make it possible to detect temporal trends in total abundance of several understudied taxonomic groups and interactions with other variables. This confirms that welldesigned participatory science adds value to large-scale biodiversity studies (Chandler et al., 2017; McKinley et al., 2017) and allows the development of indicators (Couvet, Jiguet, Julliard, Levrel, \& Teyssedre, 2008). Such design could also be used to foster arthropod conservation in farmland, which is crucial for ethical and economic reasons (FAO, 2019). Below we show that our results

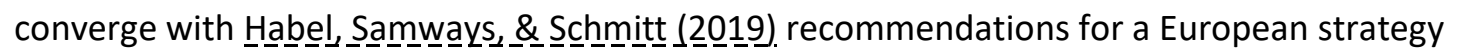
mitigating the decline of terrestrial insects, including the protection of high quality habitats for insects, ecological intensification of agriculture and the reduction and control of fertilizers and pesticides.

As discussed above, promoting participant fidelity to track the consequences of changes in farming practices should help separate the effects of pesticides versus fertilizers and identify biodiversityfriendly practices with demonstrated causative effects. Improved fidelity can be achieved by developing more user-friendly data entry interfaces, by promoting FBO in large professional networks, such as unions, or by providing more personalized feedback to participants, all of which is under way. We may also hope to see more changes in practices as a result of recent political will to reduce pesticides use or of awareness raising through participatory science (Deguines, Princé, Prévot, \& Fontaine, 2020).

Beyond the reduction of inputs, our results also suggest that arthropod conservation can be promoted via improved habitat quality, e.g. presence of old meadows or woodland. For example, we observed that the decline of beetles and molluscs in temporary meadows could be reversed, 
depending on management, in permanent meadows. This corroborates the recognized importance of permanent grasslands for biodiversity (Petters, 2015).

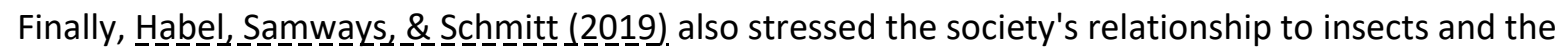
need to highlight their economic and ecological importance to help raise public awareness. One of the distinctives of FBO as a citizen science object is that it is aimed at a specific socio-professional public. The involvement of farmers in farmland biodiversity monitoring may help them acknowledge the need to take biodiversity into account in their professional practice and transform their vision of their farm (Deschamps \& Demeulenaere, 2015; Hampartzoumian et al., 2013). Participatory science through an experience-based knowledge and sharing through professional networks (McKinley et al., 2017) could be a driving force for change in agricultural practices at the farmers' scale. By providing data directly from their fields and practices (as opposed to experimental conditions), farmers took an active role in the demonstration of the effects of agriculture on its environment, which may elicit citizen involvement. Furthermore, engagement in citizen science could launch interactions between farmers and scientists to work together on new agricultural systems (Berthet, Barnaud, Girard, Labatut, \& Martin, 2016). Finally, FBO tends to serve as an exchange platform between environmentalists/naturalists and farming professionals. The program is therefore becoming a political tool for agro-ecological transition, soon providing indicators for public management and hopefully contributing in a compelling way, as an output of citizen science, to the scientific warning messages on the biodiversity crisis.

\section{Acknowledgments}

We thank all farmers who provided observations from their fields, the FBO management team (Elodie Chauvet, Marion Demade, Marine Gérardin, Romain Julliard, Christophe Pinard, Nora Rouillier) and the French Ministry of Agriculture, which supported the program. We acknowledge the E-OBS dataset from the EU-FP6 project UERRA (http://www.uerra.eu), the Copernicus Climate 
Change Service, and the data providers in the ECA\&D project (https://www.ecad.eu). We thank the INRAE MIGALE bioinformatics facility (MIGALE, INRAE, 2020. Migale bioinformatics Facility, doi: 10.15454/1.5572390655343293E12) for providing help and support. This research project was funded by the Crédit Agricole through sponsoring to OB. Finally, we thank Michael Pocock and two anonymous reviewers for constructive comments on an earlier version of this article.

\section{Authors' contributions}

EP, RLV and OB conceived the ideas and designed methodology; OB analysed the data; EP and OB led the writing of the manuscript. All authors contributed critically to the drafts and gave final approval for publication.

\section{Data availability statement}

Data is available from Zenodo (Billaud, Vermeersch, \& Porcher, 2020)

\section{References}

Berger, G., Graef, F., Pallut, B., Hoffmann, J., Brühl, C. A., \& Wagner, N. (2018). How Does Changing Pesticide Usage Over Time Affect Migrating Amphibians: A Case Study on the Use of Glyphosate-Based Herbicides in German Agriculture Over 20 Years. Frontiers in Environmental Science, 6. doi: 10.3389/fenvs.2018.00006

Berthet, E. T. A., Barnaud, C., Girard, N., Labatut, J., \& Martin, G. (2016). How to foster agroecological innovations? A comparison of participatory design methods. Journal of Environmental Planning and Management, 59(2), 280-301. doi: 10.1080/09640568.2015.1009627

Billaud, O., Vermeersch, R.-L., \& Porcher, E. (2020). Data - Citizen science involving farmers as a means to document temporal trends in farmland biodiversity and relate them to agricultural practices. [Data set]. Zenodo. doi: 10.5281/zenodo.3903128 
Bolker, B. M., Brooks, M. E., Clark, C. J., Geange, S. W., Poulsen, J. R., Stevens, M. H. H., \& White, J.-S. S. (2009). Generalized linear mixed models: a practical guide for ecology and evolution. Trends in Ecology \& Evolution, 24(3), 127-135. doi: 10.1016/j.tree.2008.10.008

Bouché, M. B. (1972). Lombriciens de France: écologie et systématique. Paris, France: Institut national de la recherche agronomique.

Brittain, C., \& Potts, S. G. (2011). The potential impacts of insecticides on the life-history traits of bees and the consequences for pollination. Basic and Applied Ecology, 12(4), 321-331. doi: 10.1016/j.baae.2010.12.004

Cardinale, B. J., Matulich, K. L., Hooper, D. U., Byrnes, J. E., Duffy, E., Gamfeldt, L., ... Gonzalez, A. (2011). The Functional Role of Producer Diversity in Ecosystems. American Journal of Botany, 98(3), 572-592. doi: 10.3732/ajb.1000364

Carrié, R., Andrieu, E., Ouin, A., \& Steffan-Dewenter, I. (2017). Interactive effects of landscape-wide intensity of farming practices and landscape complexity on wild bee diversity. Landscape Ecology, 32(8), 1631-1642. doi: 10.1007/s10980-017-0530-y

Chandler, M., See, L., Copas, K., Bonde, A. M. Z., López, B. C., Danielsen, F., ... Turak, E. (2017). Contribution of citizen science towards international biodiversity monitoring. Biological Conservation, 213, 280-294. doi: 10.1016/j.biocon.2016.09.004

Cornes, R. C., Schrier, G. van der, Besselaar, E. J. M. van den, \& Jones, P. D. (2018). An Ensemble Version of the E-OBS Temperature and Precipitation Data Sets. Journal of Geophysical Research: Atmospheres, 123(17), 9391-9409. doi: 10.1029/2017JD028200

Couvet, D., Jiguet, F., Julliard, R., Levrel, H., \& Teyssedre, A. (2008). Enhancing citizen contributions to biodiversity science and public policy. Interdisciplinary Science Reviews, 33(1), 95-103. doi: $10.1179 / 030801808 \times 260031$

Damgaard, C. (2019). A Critique of the Space-for-Time Substitution Practice in Community Ecology. Trends in Ecology \& Evolution, 34(5), 416-421. doi: 10.1016/j.tree.2019.01.013 
Deguines, N., Princé, K., Prévot, A.-C., \& Fontaine, B. (2020). Assessing the emergence of probiodiversity practices in citizen scientists of a backyard butterfly survey. Science of The Total Environment, 716, 136842. doi: 10.1016/j.scitotenv.2020.136842

Deschamps, S., \& Demeulenaere, É. (2015). L’observatoire agricole de la biodiversité. Vers un réancrage des pratiques dans leur milieu. Études rurales, (195), 109-126.

Desneux, N., Decourtye, A., \& Delpuech, J.-M. (2007). The Sublethal Effects of Pesticides on Beneficial Arthropods. Annual Review of Entomology, 52(1), 81-106. doi: 10.1146/annurev.ento.52.110405.091440

Dooren, T. J. M. V. (2019). Assessing species richness trends: Declines of bees and bumblebees in the Netherlands since 1945. Ecology and Evolution, 9(23), 13056-13068. doi: 10.1002/ece3.5717

Dover, J., \& Settele, J. (2009). The influences of landscape structure on butterfly distribution and movement: a review. Journal of Insect Conservation, 13(1), 3-27. doi: 10.1007/s10841-008$9135-8$

FAO. (2019). The State of the World's Biodiversity for Food and Agriculture. Retrieved from http://www.fao.org/3/CA3229EN/CA3229EN.pdf

Gamez-Virues, S., Perovic, D. J., Gossner, M. M., Boersching, C., Bluethgen, N., de Jong, H., ... Westphal, C. (2015). Landscape simplification filters species traits and drives biotic homogenization. Nature Communications, 6, 8568. doi: 10.1038/ncomms9568

Habel, J. C., Samways, M. J., \& Schmitt, T. (2019). Mitigating the precipitous decline of terrestrial European insects: Requirements for a new strategy. Biodiversity and Conservation, 28(6), 1343-1360. doi: 10.1007/s10531-019-01741-8

Habel, J. C., Trusch, R., Schmitt, T., Ochse, M., \& Ulrich, W. (2019). Long-term large-scale decline in relative abundances of butterfly and burnet moth species across south-western Germany. Scientific Reports, 9(1), 1-9. doi: 10.1038/s41598-019-51424-1

Haddad, N. M., Haarstad, J., \& Tilman, D. (2000). The effects of long-term nitrogen loading on grassland insect communities. Oecologia, 124(1), 73-84. doi: 10.1007/s004420050026 
Hallmann, C. A., Foppen, R. P. B., van Turnhout, C. A. M., de Kroon, H., \& Jongejans, E. (2014). Declines in insectivorous birds are associated with high neonicotinoid concentrations. Nature, 511(7509), 341-343. doi: 10.1038/nature13531

Hallmann, C. A., Sorg, M., Jongejans, E., Siepel, H., Hofland, N., Schwan, H., ... de Kroon, H. (2017). More than 75 percent decline over 27 years in total flying insect biomass in protected areas. PLOS ONE, 12(10), e0185809. doi: 10.1371/journal.pone.0185809

Hallmann, C. A., Zeegers, T., Klink, R. van, Vermeulen, R., Wielink, P. van, Spijkers, H., ... Jongejans, E. (2019). Declining abundance of beetles, moths and caddisflies in the Netherlands. Insect Conservation and Diversity, 13(2), 127-139. doi: 10.1111/icad.12377

Hampartzoumian, H., Preud'Homme, R.-L., Loïs, G., Raymond, R., Bühler, È. A., \& Hanachi, Y. (2013). L'Observatoire agricole de la biodiversité (OAB) : une pédagogie active autour d'un projet de sciences participatives. Pour, 219(3), 169. doi: 10.3917/pour.219.0169

Hartig, F. (2020). DHARMa: Residual Diagnostics for Hierarchical (Multi-Level / Mixed) Regression Models. R package version 0.3.2.0. Retrieved from https://CRAN.Rproject.org/package=DHARMa

Henry, M., Beguin, M., Requier, F., Rollin, O., Odoux, J.-F., Aupinel, P., ... Decourtye, A. (2012). A Common Pesticide Decreases Foraging Success and Survival in Honey Bees. Science, 336(6079), 348-350. doi: 10.1126/science.1215039

Hopfenmüller, S., Steffan-Dewenter, I., \& Holzschuh, A. (2014). Trait-Specific Responses of Wild Bee Communities to Landscape Composition, Configuration and Local Factors. PLOS ONE, 9(8). doi: 10.1371/journal.pone.0104439

Jackson, S. T., \& Blois, J. L. (2015). Community ecology in a changing environment: Perspectives from the Quaternary. Proceedings of the National Academy of Sciences, 112(16), 4915-4921. doi: $10.1073 /$ pnas. 1403664111 
Klink, R. van, Bowler, D. E., Gongalsky, K. B., Swengel, A. B., Gentile, A., \& Chase, J. M. (2020). Metaanalysis reveals declines in terrestrial but increases in freshwater insect abundances. Science, 368(6489), 417-420. doi: 10.1126/science.aax9931

Kratz, T. K., Deegan, L. A., Harmon, M. E., \& Lauenroth, W. K. (2003). Ecological Variability in Space and Time: Insights Gained from the US LTER Program. BioScience, 53(1), 57-67. doi: 10.1641/0006-3568(2003)053[0057:EVISAT]2.0.CO;2

Kromp, B. (1999). Carabid beetles in sustainable agriculture: a review on pest control efficacy, cultivation impacts and enhancement. Agriculture, Ecosystems \& Environment, 74(1-3), 187228. doi: 10.1016/S0167-8809(99)00037-7

Lemtiri, A., Colinet, G., Alabi, T., Cluzeau, D., Zirbes, L., Haubruge, E., \& Francis, F. (2014). Impacts of earthworms on soil components and dynamics. A review. Biotechnologie Agronomie Societe Et Environnement, 18(1), 121-133.

Lüdecke, D. (2018). ggeffects: Tidy Data Frames of Marginal Effects from Regression Models. Journal of Open Source Software, 3(26), 772. doi: 10.21105/joss.00772

Lüdecke, D., Makowski, D., Waggoner, P., \& Patil, I. (2020). Assessment of Regression Models Performance. Retrieved from https://easystats.github.io/performance

McKinley, D. C., Miller-Rushing, A. J., Ballard, H. L., Bonney, R., Brown, H., Cook-Patton, S. C., ... Soukup, M. A. (2017). Citizen science can improve conservation science, natural resource management, and environmental protection. Biological Conservation, 208, 15-28. doi: 10.1016/j.biocon.2016.05.015

Mulé, R., Sabella, G., Robba, L., \& Manachini, B. (2017). Systematic Review of the Effects of Chemical Insecticides on Four Common Butterfly Families. Frontiers in Environmental Science, 5. doi: 10.3389/fenvs.2017.00032

Muratet, A., \& Fontaine, B. (2015). Contrasting impacts of pesticides on butterflies and bumblebees in private gardens in France. Biological Conservation, 182, 148-154. doi: 10.1016/j.biocon.2014.11.045 
Nakagawa, S., Johnson, P. C. D., \& Schielzeth, H. (2017). The coefficient of determination R2 and intra-class correlation coefficient from generalized linear mixed-effects models revisited and expanded. Journal of The Royal Society Interface, 14(134), 20170213. doi: 10.1098/rsif.2017.0213

Nilsson, S. G., Franzen, M., \& Pettersson, L. B. (2013). Land-use changes, farm management and the decline of butterflies associated with semi-natural grasslands in southern Sweden. Nature Conservation-Bulgaria, (6), 31-48. doi: 10.3897/natureconservation.6.5205

Pereira, H. M., Ferrier, S., Walters, M., Geller, G. N., Jongman, R. H. G., Scholes, R. J., ... Wegmann, M. (2013). Essential Biodiversity Variables. Science, 339(6117), 277-278. doi: 10.1126/science.1229931

Petters, A. (2015). Environmental impacts and future challenges of grasslands and grasslandbased livestock production systems in Europe. In P. K. Ghosh, S. K. Mahanta, J. B. Singh, \& P. S. Pathak (Eds.), Grassland : a global ressource perspective (International Grassland Congress and Range Management Society of IndiaArmy Printing Press, pp. 365-390). Lucknow, India: Army Printing Press.

Pickett, S. T. A. (1989). Space-for-Time Substitution as an Alternative to Long-Term Studies. In G. E. Likens (Ed.), Long-Term Studies in Ecology: Approaches and Alternatives (pp. 110-135). New York, NY: Springer New York. doi: 10.1007/978-1-4615-7358-6_5

Ponge, J.-F., Pérès, G., Guernion, M., Ruiz-Camacho, N., Cortet, J., Pernin, C., ... Cluzeau, D. (2013). The impact of agricultural practices on soil biota: A regional study. Soil Biology and Biochemistry, 67, 271-284. doi: 10.1016/j.soilbio.2013.08.026

Potts, S. G., Imperatriz-Fonseca, V., Ngo, H. T., Aizen, M. A., Biesmeijer, J. C., Breeze, T. D., ... Vanbergen, A. J. (2016). Safeguarding pollinators and their values to human well-being. Nature, 540(7632), 220-229. doi: 10.1038/nature20588 
Roger-Estrade, J., Anger, C., Bertrand, M., \& Richard, G. (2010). Tillage and soil ecology: Partners for sustainable agriculture. Soil and Tillage Research, 111(1), 33-40. doi: 10.1016/j.still.2010.08.010

Sánchez-Bayo, F., \& Wyckhuys, K. A. G. (2019). Worldwide decline of the entomofauna: A review of its drivers. Biological Conservation, 232, 8-27. doi: 10.1016/j.biocon.2019.01.020

Schmucki, R. (2020). climateExtract: Extract Climate Data From a Local NETCDF File. R package version 1.18.0.

Seibold, S., Gossner, M. M., Simons, N. K., Blüthgen, N., Müller, J., Ambarlı, D., ... Weisser, W. W. (2019). Arthropod decline in grasslands and forests is associated with landscape-level drivers. Nature, 574(7780), 671-674. doi: 10.1038/s41586-019-1684-3

Stanton, R. L., Morrissey, C. A., \& Clark, R. G. (2018). Analysis of trends and agricultural drivers of farmland bird declines in North America: A review. Agriculture, Ecosystems \& Environment, 254, 244-254. doi: 10.1016/j.agee.2017.11.028

Symondson, W. O. C., Sunderland, K. D., \& Greenstone, M. H. (2002). Can generalist predators be effective biocontrol agents? Annual Review of Entomology, 47, 561-594. doi: 10.1146/annurev.ento.47.091201.145240

Voeten, C. C. (2020). buildmer: Stepwise Elimination and Term Reordering for Mixed-Effects Regression. $R$ package version 1.6. Retrieved from https://CRAN.Rproject.org/package=buildmer

Winfree, R., Griswold, T., \& Kremen, C. (2007). Effect of Human Disturbance on Bee Communities in a Forested Ecosystem. Conservation Biology, 21(1), 213-223. doi: 10.1111/j.15231739.2006.00574.x

Winfree, R., Williams, N. M., Dushoff, J., \& Kremen, C. (2007). Native bees provide insurance against ongoing honey bee losses. Ecology Letters, 10(11), 1105-1113. doi: 10.1111/j.14610248.2007.01110.x 
599 Zaller, J. G., \& Brühl, C. A. (2019). Editorial: Non-target Effects of Pesticides on Organisms Inhabiting 600 Agroecosystems. Frontiers in Environmental Science, 7. doi: 10.3389/fenvs.2019.00075

601 
Table 1. Results of the GLMM models on abundance of solitary bees for each crop type, using the PCA coordinates as proxy for farming practices and the MCA coordinates as proxy for landscape characteristics. PCA axis 1 stands for chemical treatment and axis 2 for organic fertilization in field crops, vineyards and orchards (Fig.1 C-D-F), while the reverse is true in meadows. The first axis of MCA represents proximity to woodland; the interpretation of the second axis is more variable (see main text and Fig. S4-5-6-7). Values are log-coefficients, followed by their significance (stars).

Marginal and conditional $R^{2}$ give the variance explained by the model with and without the random "field" effect of the model (with variance $\sigma^{2}$ ).

\begin{tabular}{lcccc}
\hline Bees & Field crops & Meadows & Vineyards & Orchards \\
\hline Year, landscape, practices & & & & \\
Year & $-0.21^{* * *}$ & -0.13 & 0.05 & $-0.38^{* *}$ \\
MCA1 & $0.24^{* * *}$ & 0.19 & 0.07 & 0.34 \\
MCA2 & $\mathrm{n} / \mathrm{a}$ & $-0.34^{* * *}$ & $-0.22^{*}$ & -0.13 \\
PCA1 & $-0.16^{*}$ & $0.22^{*}$ & 0.16 & 0.15 \\
PCA2 & $-0.21^{* *}$ & $\mathrm{n} / \mathrm{a}$ & $\mathrm{n} / \mathrm{a}$ & $-0.67^{* * *}$ \\
Meadows' use: Mix & $\mathrm{n} / \mathrm{a}$ & 0.29 & $\mathrm{n} / \mathrm{a}$ & $\mathrm{n} / \mathrm{a}$ \\
Meadows' use: Pasture & $\mathrm{n} / \mathrm{a}$ & $-0.73^{* * *}$ & $\mathrm{n} / \mathrm{a}$ & $\mathrm{n} / \mathrm{a}$ \\
Inter-rows: Partly grassy & $\mathrm{n} / \mathrm{a}$ & $\mathrm{n} / \mathrm{a}$ & -0.05 & $\mathrm{n} / \mathrm{a}$ \\
Inter-rows: Bare & $\mathrm{n} / \mathrm{a}$ & $\mathrm{n} / \mathrm{a}$ & $-0.76^{* *}$ & $\mathrm{n} / \mathrm{a}$ \\
\hline Interactions & & & & \\
Year*PCA1 & $-0.28^{* * *}$ & $0.22^{*}$ & $\mathrm{n} / \mathrm{a}$ & $-0.38^{* *}$ \\
Year*PCA2 & $0.15^{*}$ & $\mathrm{n} / \mathrm{a}$ & $\mathrm{n} / \mathrm{a}$ & $\mathrm{n} / \mathrm{a}$ \\
Year ${ }^{*}$ MCA1 & $\mathrm{n} / \mathrm{a}$ & $-0.19^{*}$ & $0.24^{* * *}$ & $-0.27^{*}$ \\
Year ${ }^{*}$ MCA2 & $\mathrm{n} / \mathrm{a}$ & $\mathrm{n} / \mathrm{a}$ & $-0.16^{*}$ & $0.37^{* *}$ \\
\hline Covariates & & & & \\
Degree days & & & & \\
Degree days ${ }^{*}$ & $2.05^{* * *}$ & $2.54^{* * *}$ & $2.50^{* * *}$ & $2.13^{* * *}$ \\
Longitude & $-1.26^{* * *}$ & $-1.74^{* * *}$ & $-1.63^{* * *}$ & $-1.57^{* * *}$ \\
Latitude & $0.40^{* * *}$ & $0.37^{* * *}$ & $0.39^{* *}$ & $0.57^{* * *}$ \\
Vegetation height & $-0.42^{* * *}$ & -0.20 & $\mathrm{n} / \mathrm{a}$ & $\mathrm{n} / \mathrm{a}$ \\
Installation date & $0.26^{* * *}$ & $\mathrm{n} / \mathrm{a}$ & $0.13^{*}$ & $\mathrm{n} / \mathrm{a}$ \\
\hline$\sigma^{2}$ & $-0.11^{*}$ & $-0.32^{* * *}$ & $-0.19^{*}$ & -0.26 \\
\hline Marginal ${ }^{2} /$ Conditional $\mathrm{R}^{2}$ & 3.73 & 2.68 & 2.79 & 2.98 \\
& $0.223 / 0.839$ & $0.289 / 0.829$ & $0.238 / 0.801$ & $0.306 / 0.829$ \\
\hline \hline
\end{tabular}


Table 2. Results of the GLMM models on abundance of butterflies for each crop type, using the PCA

614 coordinates as proxy for farming practices. PCA, MCA axes and all symbols as in Table 1.

\begin{tabular}{|c|c|c|c|c|}
\hline Butterflies & Field crops & Meadows & Vineyards & Orchards \\
\hline \multicolumn{5}{|l|}{ Year, landscape, practices } \\
\hline Year & -0.05 & $0.19^{* * *}$ & $-0.14^{*}$ & $n / a$ \\
\hline MCA1 & $\mathrm{n} / \mathrm{a}$ & $-0.18^{* *}$ & $n / a$ & $\mathrm{n} / \mathrm{a}$ \\
\hline MCA2 & $\mathrm{n} / \mathrm{a}$ & -0.13 & $\mathrm{n} / \mathrm{a}$ & $\mathrm{n} / \mathrm{a}$ \\
\hline PCA1 & 0.01 & $\mathrm{n} / \mathrm{a}$ & $\mathrm{n} / \mathrm{a}$ & $\mathrm{n} / \mathrm{a}$ \\
\hline Inter-rows: Partly grassy & $\mathrm{n} / \mathrm{a}$ & $\mathrm{n} / \mathrm{a}$ & -0.16 & $n / a$ \\
\hline Inter-rows: Bare & $\mathrm{n} / \mathrm{a}$ & $\mathrm{n} / \mathrm{a}$ & $-0.79^{* * *}$ & n/a \\
\hline \multicolumn{5}{|l|}{ Interactions } \\
\hline Year*PCA1 & $-0.09^{*}$ & $\mathrm{n} / \mathrm{a}$ & $\mathrm{n} / \mathrm{a}$ & $\mathrm{n} / \mathrm{a}$ \\
\hline Year *MCA2 & $\mathrm{n} / \mathrm{a}$ & $0.14^{* *}$ & $\mathrm{n} / \mathrm{a}$ & $\mathrm{n} / \mathrm{a}$ \\
\hline \multicolumn{5}{|l|}{ Covariates } \\
\hline Degree days & $1.69^{* * *}$ & $1.31^{* * *}$ & $0.94^{* * *}$ & $1.80^{* * *}$ \\
\hline Degree days ${ }^{2}$ & $-1.51^{* * *}$ & $-1.23^{* * *}$ & $-1.02^{* * *}$ & $-1.77^{* * *}$ \\
\hline Latitude & $-0.18^{* * *}$ & $-0.29^{* * *}$ & $-0.38^{* * *}$ & $\mathrm{n} / \mathrm{a}$ \\
\hline Longitude & $\mathrm{n} / \mathrm{a}$ & $\mathrm{n} / \mathrm{a}$ & $0.24^{* *}$ & $\mathrm{n} / \mathrm{a}$ \\
\hline Cloud cover: Sunny & $0.59^{* * *}$ & $0.70^{* * *}$ & 0.4 & $n / a$ \\
\hline Cloud cover: Slightly cloudy & $0.53^{* * *}$ & $0.45^{*}$ & 0.54 & $n / a$ \\
\hline Cloud cover: Thin overcast & $0.43^{* *}$ & $0.94^{* * *}$ & 0.58 & $\mathrm{n} / \mathrm{a}$ \\
\hline Cloud cover: Cloudy & $0.35^{* *}$ & $0.47^{*}$ & 0.13 & $\mathrm{n} / \mathrm{a}$ \\
\hline Cloud cover: Very cloudy & 0.08 & -0.18 & -0.64 & $\mathrm{n} / \mathrm{a}$ \\
\hline Wind: Light & $0.56^{* * *}$ & $0.46^{* *}$ & $\mathrm{n} / \mathrm{a}$ & $\mathrm{n} / \mathrm{a}$ \\
\hline Wind: No & $0.67^{* * *}$ & 0.26 & $\mathrm{n} / \mathrm{a}$ & $\mathrm{n} / \mathrm{a}$ \\
\hline$\sigma^{2}$ & 0.46 & 0.43 & 0.67 & 0.4 \\
\hline Marginal $\mathrm{R}^{2}$ / Conditional $\mathrm{R}^{2}$ & $0.262 / 0.601$ & $0.252 / 0.566$ & $0.243 / 0.707$ & $0.188 / 0.529$ \\
\hline
\end{tabular}


617 Table 3. Results of the GLM models on abundance of earthworms for each crop type, using the PCA

618 coordinates as proxy for farming practices. PCA, MCA axes and all symbols as in Table 1.

\begin{tabular}{lcc}
\hline Earthworms & Field crops & Meadows \\
\hline Year, landscape, practices & \multicolumn{2}{c}{} \\
Year & $\mathrm{n} / \mathrm{a}$ & $-0.26^{* * *}$ \\
PCA1 & $\mathrm{n} / \mathrm{a}$ & $0.18^{* *}$ \\
Tillage: Deep ploughing & $-0.28^{*}$ & $\mathrm{n} / \mathrm{a}$ \\
Tillage: Direct sowing & $0.81^{* * *}$ & $\mathrm{n} / \mathrm{a}$ \\
Meadow's age & $\mathrm{n} / \mathrm{a}$ & $0.26^{* * *}$ \\
\hline Covariates & & \\
Degree days & $-0.13^{*}$ & $-0.13^{*}$ \\
Soil humidity: Waterlogged & 0.56 & $-1.58^{* *}$ \\
Soil humidity: Wet & -0.09 & -0.67 \\
Soil humidity: Dried & 0.06 & 0.27 \\
Soil humidity: Dry & $-0.69^{*}$ & -0.35 \\
\hline \hline
\end{tabular}


621 Table 4. Results of the GLMM models on abundance of beetles for each crop type, using the PCA

622 coordinates as proxy for farming practices. PCA, MCA axes and all symbols as in Table 1.

\begin{tabular}{|c|c|c|c|c|}
\hline Beetles & Field crops & Meadows & Vineyards & Orchards \\
\hline \multicolumn{5}{|l|}{ Year, landscape, practices } \\
\hline Year & $0.24^{* * *}$ & $-0.28^{*}$ & $0.29^{* * *}$ & $-0.93^{* * *}$ \\
\hline PCA1 & $0.18^{* * *}$ & $0.58^{* * *}$ & $0.20^{*}$ & $0.88^{* * *}$ \\
\hline PCA2 & -0.04 & $0.34^{*}$ & $\mathrm{n} / \mathrm{a}$ & $\mathrm{n} / \mathrm{a}$ \\
\hline Meadows' type: Permanent & $\mathrm{n} / \mathrm{a}$ & -0.15 & $n / a$ & $\mathrm{n} / \mathrm{a}$ \\
\hline \multicolumn{5}{|l|}{ Interactions } \\
\hline Year*PCA1 & $\mathrm{n} / \mathrm{a}$ & $-0.37^{* *}$ & $\mathrm{n} / \mathrm{a}$ & $-0.49^{* * *}$ \\
\hline Year*PCA2 & $0.17^{* * *}$ & $0.30^{*}$ & $\mathrm{n} / \mathrm{a}$ & $\mathrm{n} / \mathrm{a}$ \\
\hline Year*(Meadows' type: Permanent) & $\mathrm{n} / \mathrm{a}$ & $0.80^{* * *}$ & $\mathrm{n} / \mathrm{a}$ & $\mathrm{n} / \mathrm{a}$ \\
\hline \multicolumn{5}{|l|}{ Covariates } \\
\hline Degree days & $\mathrm{n} / \mathrm{a}$ & $-0.14^{* * *}$ & $-0.25^{* * *}$ & $-0.20^{* * *}$ \\
\hline Degree days ${ }^{2}$ & $-0.10^{* * *}$ & $\mathrm{n} / \mathrm{a}$ & $\mathrm{n} / \mathrm{a}$ & $\mathrm{n} / \mathrm{a}$ \\
\hline Latitude & $0.22^{* * *}$ & $\mathrm{n} / \mathrm{a}$ & $0.62^{* * *}$ & $\mathrm{n} / \mathrm{a}$ \\
\hline Installation date & $\mathrm{n} / \mathrm{a}$ & $-0.34^{* *}$ & $0.22^{*}$ & $\mathrm{n} / \mathrm{a}$ \\
\hline Board humidity: Dried & $-0.36^{* * *}$ & $\mathrm{n} / \mathrm{a}$ & $0.61^{* * *}$ & -0.20 \\
\hline Board humidity: Dry & $-0.45^{* * *}$ & $\mathrm{n} / \mathrm{a}$ & $0.68^{* * *}$ & $0.47^{*}$ \\
\hline$\sigma^{2}$ & 1.21 & 1.83 & 1.70 & 1.60 \\
\hline Marginal $\mathrm{R}^{2} /$ Conditional $\mathrm{R}^{2}$ & $0.069 / 0.594$ & $0.124 / 0.711$ & $0.127 / 0.472$ & $0.169 / 0.750$ \\
\hline
\end{tabular}

624 
Table 5. Results of the GLMM models on abundance of molluscs for each crop type, using the PCA

627 coordinates as proxy for farming practices. PCA, MCA axes and all symbols as in Table 1.

\begin{tabular}{|c|c|c|c|c|}
\hline Mollusks & Field crops & Meadows & Vineyards & Orchards \\
\hline \multicolumn{5}{|l|}{ Year, landscape, practices } \\
\hline Year & $0.50^{* * *}$ & $-0.43^{* * *}$ & $0.15^{*}$ & $-0.14^{*}$ \\
\hline MCA2 & $0.09^{* * *}$ & $\mathrm{n} / \mathrm{a}$ & $\mathrm{n} / \mathrm{a}$ & $\mathrm{n} / \mathrm{a}$ \\
\hline PCA1 & -0.01 & 0.09 & 0.18 & $0.34^{*}$ \\
\hline PCA2 & 0.07 & 0.17 & -0.14 & $-0.17^{* *}$ \\
\hline Tillage: Deep ploughing & -0.04 & $\mathrm{n} / \mathrm{a}$ & $\mathrm{n} / \mathrm{a}$ & $\mathrm{n} / \mathrm{a}$ \\
\hline Tillage: Direct sowing & $0.52^{* *}$ & $\mathrm{n} / \mathrm{a}$ & $\mathrm{n} / \mathrm{a}$ & $\mathrm{n} / \mathrm{a}$ \\
\hline Inter-rows: Partly grassy & $\mathrm{n} / \mathrm{a}$ & $\mathrm{n} / \mathrm{a}$ & 0.29 & 0.29 \\
\hline Inter-rows: Bare & $\mathrm{n} / \mathrm{a}$ & $\mathrm{n} / \mathrm{a}$ & $-0.85^{* *}$ & $-1.13^{* * *}$ \\
\hline Meadows' type: Permanent & $\mathrm{n} / \mathrm{a}$ & 0.11 & $\mathrm{n} / \mathrm{a}$ & $\mathrm{n} / \mathrm{a}$ \\
\hline Meadows' use: Mix & $\mathrm{n} / \mathrm{a}$ & $-0.45^{* *}$ & $\mathrm{n} / \mathrm{a}$ & $\mathrm{n} / \mathrm{a}$ \\
\hline Meadows' use: Pasture & $\mathrm{n} / \mathrm{a}$ & 0.32 & $\mathrm{n} / \mathrm{a}$ & $\mathrm{n} / \mathrm{a}$ \\
\hline \multicolumn{5}{|l|}{ Interactions } \\
\hline Year*PCA1 & $0.10^{*}$ & $-0.67^{* * *}$ & $0.22^{* *}$ & $-0.17^{*}$ \\
\hline Year*PCA2 & $-0.27^{* * *}$ & $0.35^{* * *}$ & $-0.35^{* * *}$ & $\mathrm{n} / \mathrm{a}$ \\
\hline Year*(Tillage: Deep ploughing) & $-0.19^{*}$ & $\mathrm{n} / \mathrm{a}$ & $\mathrm{n} / \mathrm{a}$ & $\mathrm{n} / \mathrm{a}$ \\
\hline Year*(Tillage: Direct sowing) & 0.12 & $\mathrm{n} / \mathrm{a}$ & $\mathrm{n} / \mathrm{a}$ & $\mathrm{n} / \mathrm{a}$ \\
\hline Year*(Meadows' use: Mix) & $\mathrm{n} / \mathrm{a}$ & $0.32^{*}$ & $\mathrm{n} / \mathrm{a}$ & $\mathrm{n} / \mathrm{a}$ \\
\hline Year*(Meadows' use: Pasture) & $\mathrm{n} / \mathrm{a}$ & 0.03 & $\mathrm{n} / \mathrm{a}$ & $\mathrm{n} / \mathrm{a}$ \\
\hline Year*(Meadows' type: Permanent) & $\mathrm{n} / \mathrm{a}$ & $0.91^{* * *}$ & $\mathrm{n} / \mathrm{a}$ & $\mathrm{n} / \mathrm{a}$ \\
\hline \multicolumn{5}{|l|}{ Covariates } \\
\hline Degree days & $-0.70^{* * *}$ & $-1.06^{* * *}$ & $-0.48^{* * *}$ & $-0.75^{* * *}$ \\
\hline Degree days ${ }^{2}$ & $0.60^{* * *}$ & $0.84^{* * *}$ & $0.45^{* * *}$ & $0.52^{* * *}$ \\
\hline Longitude & $\mathrm{n} / \mathrm{a}$ & $\mathrm{n} / \mathrm{a}$ & $0.42^{* *}$ & $\mathrm{n} / \mathrm{a}$ \\
\hline Board humidity: Dried & -0.05 & $-0.30^{* * *}$ & 0.15 & $\mathrm{n} / \mathrm{a}$ \\
\hline Board humidity: Dry & $-0.46^{* * *}$ & $-0.42^{* * *}$ & $-0.30^{* *}$ & $\mathrm{n} / \mathrm{a}$ \\
\hline Board soil: Grassy & $0.19^{* *}$ & $\mathrm{n} / \mathrm{a}$ & $0.29^{* *}$ & $\mathrm{n} / \mathrm{a}$ \\
\hline$\sigma^{2}$ & 1.12 & 0.82 & 1.03 & 0.80 \\
\hline Marginal $\mathrm{R}^{2}$ / Conditional $\mathrm{R}^{2}$ & $0.163 / 0.641$ & $0.227 / 0.769$ & $0.116 / 0.728$ & $0.112 / 0.745$ \\
\hline
\end{tabular}



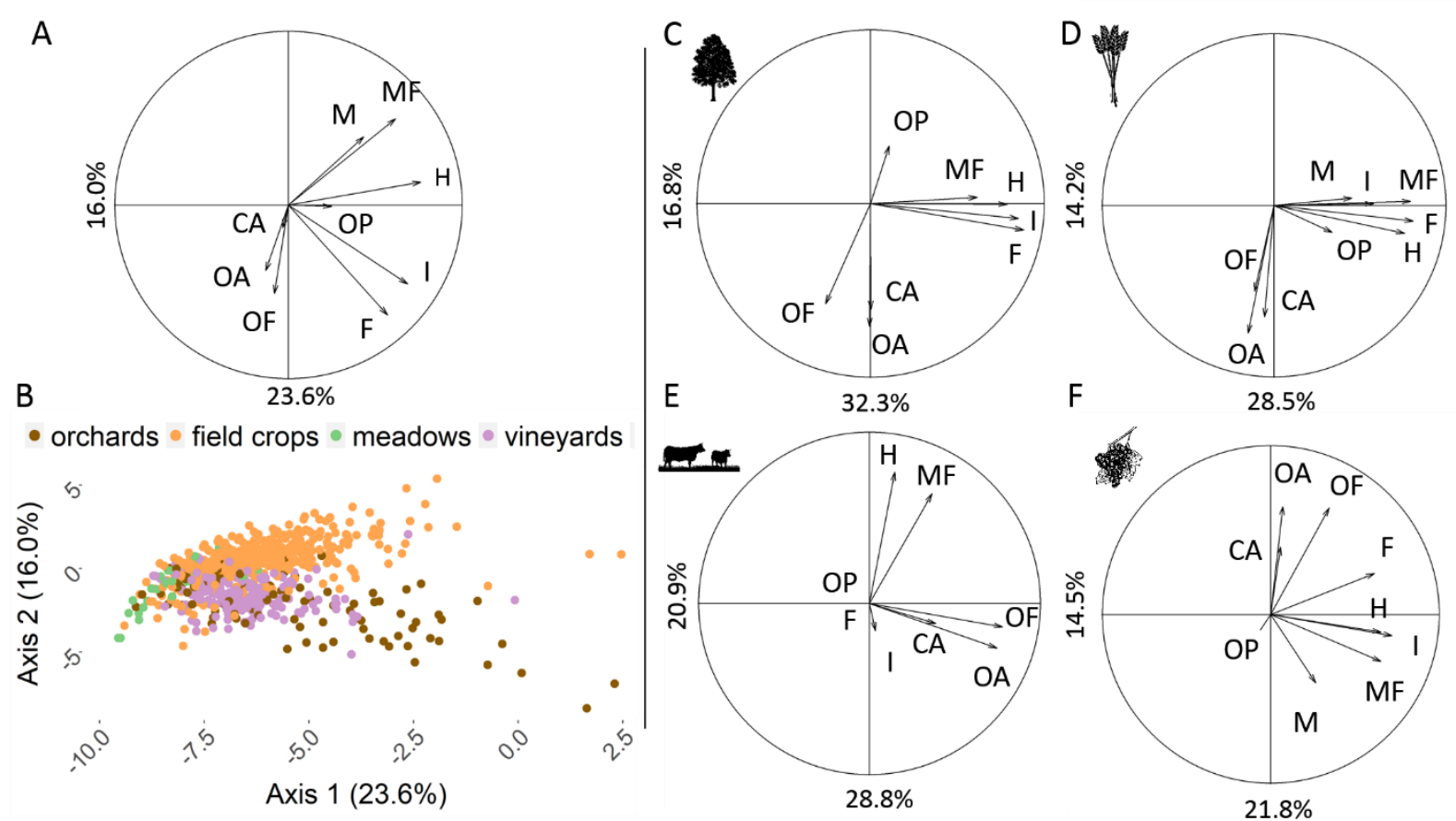

631 Figure 1. Principal Component Analysis on farming practices over all crop types (A-B) or within crop types (C orchards, D field crops, E meadows, F vineyards). Panels A and C-F show the correlation circles, with the fraction of variance explained by the first two axes. Abbreviations: $\mathrm{H}$ herbicide, $\mathrm{F}$

634 fungicide, I insecticide, M molluscicide, OP other pesticides, MF mineral fertilization, OF organic

635 fertilization, OA organic amendment, CA calcium amendment. Panel B shows the distribution of the

636 fields with different crop types along the two axes. 

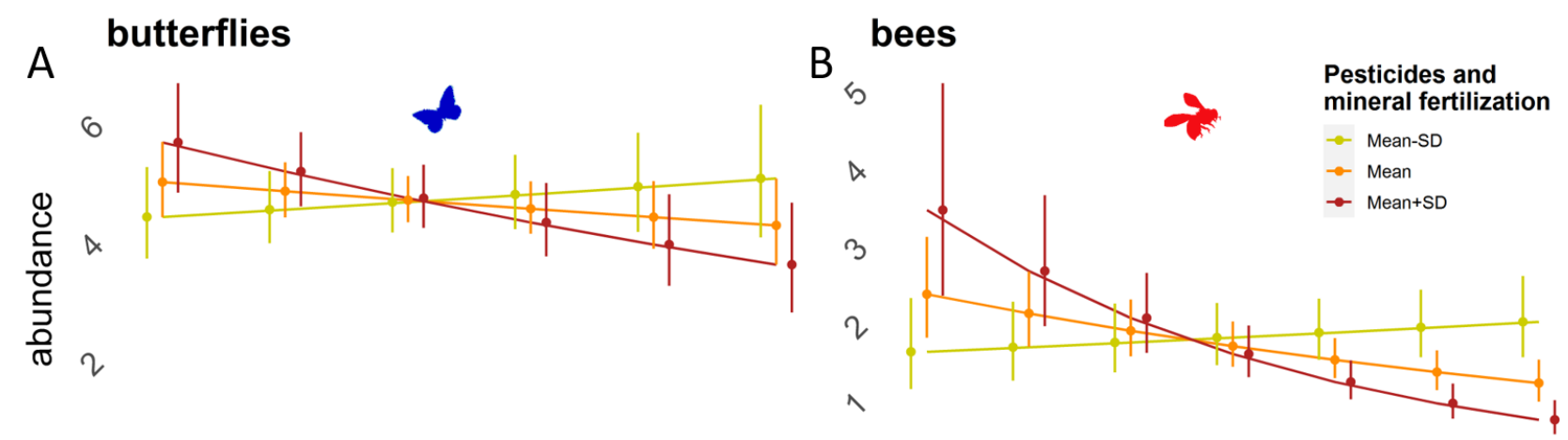

0

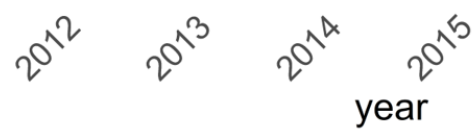

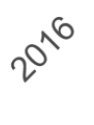

0

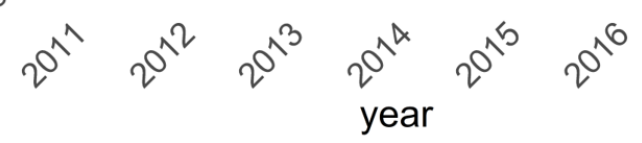

639 Figure 2. Relationship between synthetic inputs (pesticide and mineral fertilization use) and temporal

640 trends in butterfly (A) and bee (B) abundance in field crops. Use of synthetic inputs is characterized

641 here by the coordinates of the first PCA axis (Fig. 1D), from high levels (red line: mean plus one

642 standard deviation), through medium levels (orange line: mean) to low values (yellow line: mean

643 minus one standard deviation). Other variables are at their mean (quantitative terms) or

644 representative levels (qualitative terms). 
A

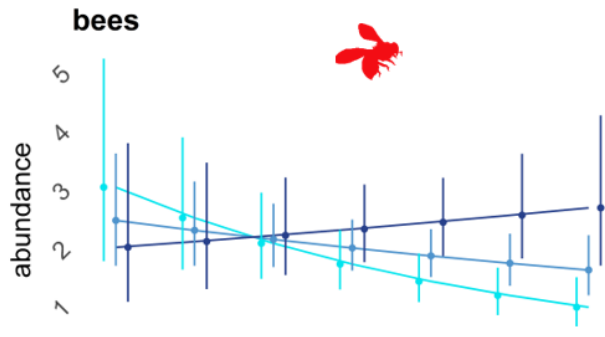

0

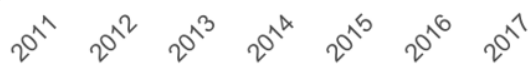

C mollusks, permanent meadows

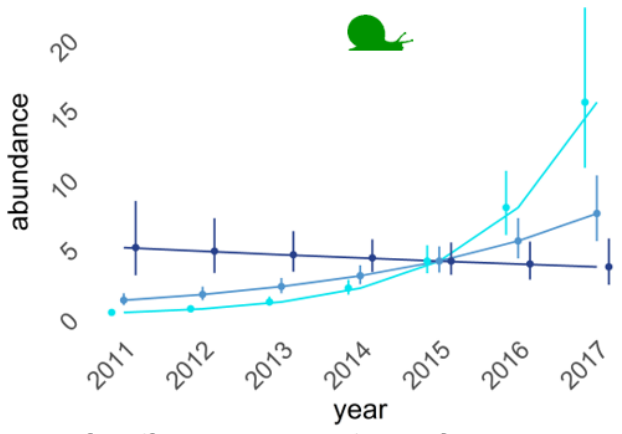

E

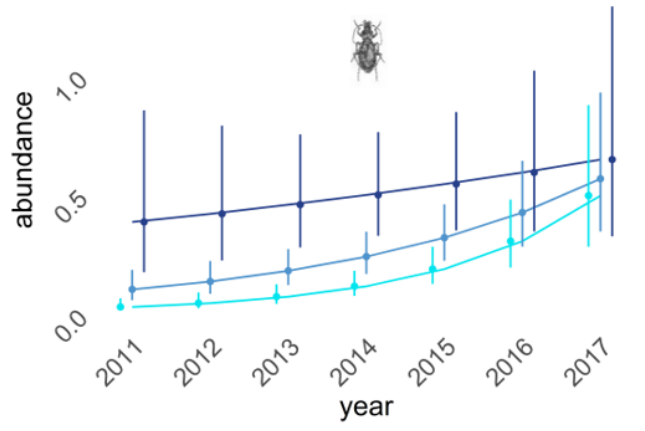

B

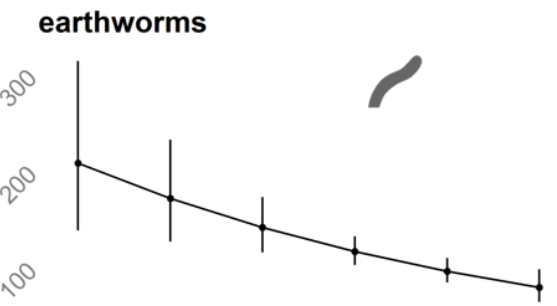

D mollusks, temporary meadows

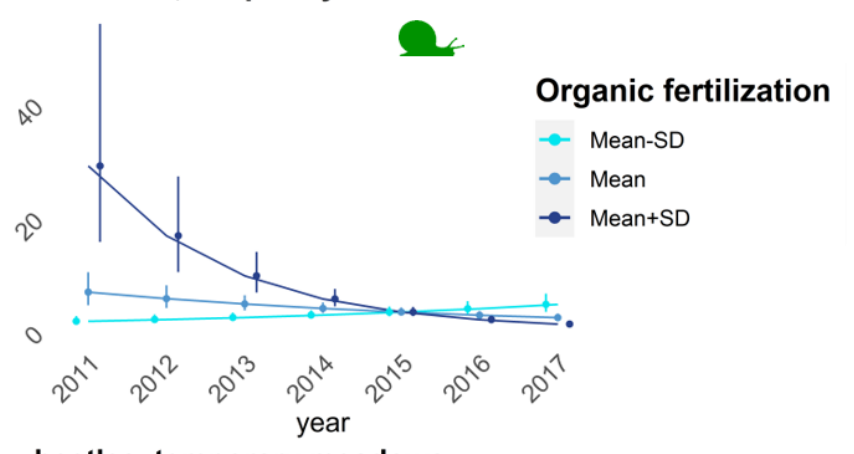

F beetles, temporary meadows

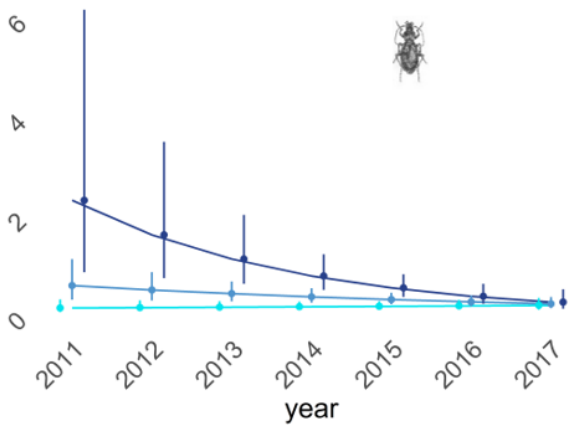

647 Figure 3. Relationship between organic fertilization and temporal trends in meadows. Organic

648 fertilization is characterized here by the coordinates of the first PCA axis (Fig. 1E), from high levels

649 (dark blue line: mean plus one standard deviation), through medium levels (blue line: mean) to low

650 values (light blue line: mean minus one standard deviation). Other variables are at their mean

651 (quantitative terms) or representative levels (qualitative terms). Beetle and mollusk abundance are predicted in permanent (C-E) and temporary meadows (D-F). 


\section{vineyards}

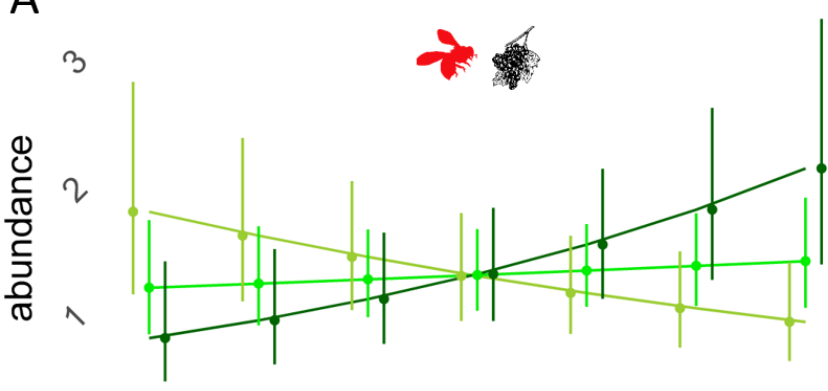

0

655

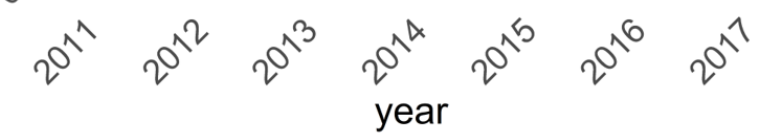

meadows

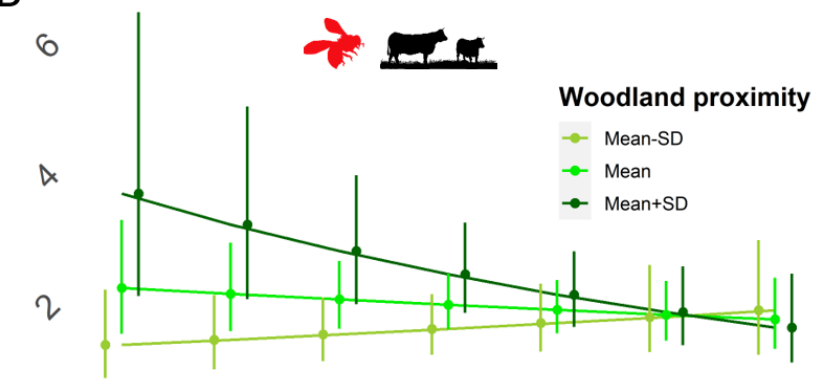

0

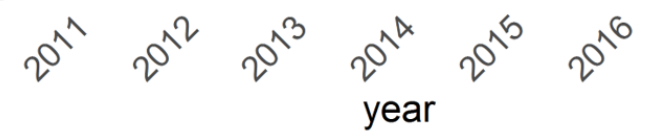

656 Figure 4. Relationship between landscape (woodland proximity) and temporal trends in bee

657 abundance in vineyards (A) and meadows (B). Woodland proximity is characterized here by the coordinates of the first MCA axis (Fig. S4), from high levels (dark green line: mean plus one standard deviation), through medium levels (green line: mean) to low values (light green line: mean minus one standard deviation). Other variables are at their mean (quantitative terms) or representative levels (qualitative terms). Predicts are computed from models using the PCA as proxy for practices. 